\title{
Effect of different shapes of holes on energy dissipation through perpendicular screen
}

\author{
Mahmoud Izzat Mahmoud ${ }^{1}$, Shahin Saber Ahmed ${ }^{2}$, Ahmed Sa'adi Al-Fahal ${ }^{1}$ \\ ${ }^{1}$ Engineering College, Tikrit University, Iraq. \\ ${ }^{2}$ College of Engineering, University of Salahaddin, Iraq.
}

Rec. 19 Dec, 2012 Accept. 22 Jan, 2013

\begin{abstract}
Previous studies have shown that screens may be utilized efficiently for dissipating the energy of water. For the present study, a series of experimental works were conducted to investigate the effect of different shapes of holes with perpendicular screen on the energy dissipation through screens. Water flowing beneath a sluice gate is used to simulate the flow downstream of a hydraulic structure. In the present study, single and double screen arrangements with porosity of $40 \%$ and inclination angle of $90^{\circ}$ was used. Circular and square holes were used during the study. The major parameters for the present study are upstream flow depth, different shape of holes, location of the screen together with the supercritical upstream flow, Froude number for a range covering from 5.0 to 25 . The gate opening simulating a hydraulic structure is adjusted at heights of $1 \mathrm{~cm}, 2 \mathrm{~cm}$ and $3 \mathrm{~cm}$ during the experiments work. The results showed that the screen with square holes is better than screen with circular holes. In addition, the results revealed that increase in the relative screen position $(\mathbf{X} / \mathbf{d})$ decreases screen effect to dissipate energy, as well as screen thickness has no significant additional contribution on the energy dissipation. As we concluded relations between the performance and efficiency of the system and screen with Froude number at the point $\mathrm{G}\left(\mathbf{F r}_{\mathbf{G}}\right)$ and has also been drawing relations between the performance of the system with $\left(\mathbf{F r}_{\mathbf{G}}\right)$ and relations between efficiency of the system and $\left(\mathbf{F r}_{\mathbf{G}}\right)$ as well as between the performance of Perforated screen with $\left(\mathbf{F r}_{\mathbf{G}}\right)$ and the efficiency of Perforated screen with $\left(\mathbf{F r}_{\mathbf{G}}\right)$
\end{abstract}

Keywords: Screen, energy dissipation, circular holes, square holes, hydraulic jump, supercritical flow.

\section{Introduction}

The study of water energy is very important in water resources engineering, design of hydraulic structures, analyses of river mechanics problems, the development of water control works, and to the life and works of humans. Most of the efforts of the engineers have been on the controlling of that energy. These efforts have resulted in developing control structures, which are sometimes used to dissipate energy and its destructive effects and sometimes to utilize this energy for the benefit of the society (Balkış, G. 2004). Screens or porous baffles, have been used in the past for various purposes. The recent studies have shown them to be efficient tools also as an energy dissipater. In order to increase the efficiency, that is, the energy dissipation capability, different models of screens are tested in order to broaden the view on the performance of screens as an alternative method for energy dissipation. Laboratory work done so far suggests that the screens or porous baffles might be useful for energy dissipation downstream of small hydraulic structures (Bozkuş, Z., Çakır, P., Ger, M. and Özeren, Y. 2004).

The porous screens are commonly used in fluid domain to dissipate wave energy for preventing from direct wave impact in downstream of structure.

An important phenomenon that occurred during the process of fluid flowing through a porous structure is the energy loss. Part of the

\footnotetext{
* Corresponding author:

Dr. Mahmoud Izzat Mahmoud
}

$凶$ mimahmoud@yahoo.com 
energy losses are caused by the friction of the opening holes as fluid passing through them and the other part of energy losses are the result of the turbulence enhanced energy dissipation behind the porous structure. For the design and application purpose, it is essential to find ways in estimating the total energy losses under conditions those fluids (Ted Chu, Graduate Mentor and K.H. Wang, Faculty Mentor, 2007).

The study used as simulation of unsteady flows in open channels under sluice gate in Laboratory hydraulic engineering, under very simplified conditions. The subject has gained an entirely new dimension in this study and the characteristics have been studied for flow conditions in hydraulic study.

\section{Theoretical Analysis:}

\section{1- Theoretical aspect:}

To be able to scrutinize the effect of screens on the behavior of flow downstream of a gate, several preliminary experiments were performed. It is observed that a supercritical flow may show two distinct behaviors when it encounters a screen.

\section{Case one:}

The screen may lead to a jump such that the jump takes place far upstream of the screen. In other words, the screen is in the fully subcritical region. That is to say, the effectiveness of the screen as a mean of energy dissipater is minimal. Since the aim of this study is to investigate the effectiveness of the screen this case is left out of the scope.

\section{Case two:}

The flow may impinge to the screen. Depending upon the Froude number the impinging jet either passes through the screen with some splashes back or may enforce a jump like behavior such that the screen is located within the zone which may be considered the roller zone if it were a jump. In either case, there is significant

amount of energy dissipation. In other words, for both type of behaviors, there is

pseudo-jump formation ,photo (1) shown the screen behavior with hydraulic jump. For the analysis of this pseudo-jump formation the following conceptual frame is constructed (figure 1) (Çakır, P. 2003).

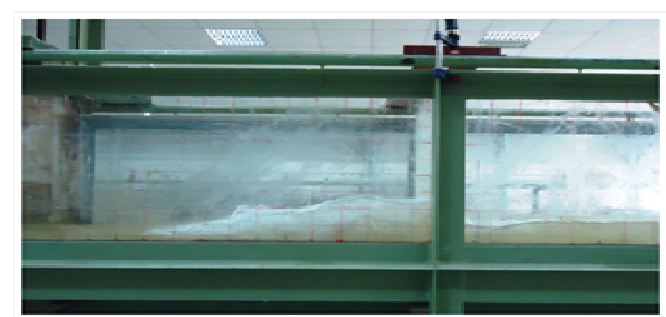

Photo (1): Sample view for upstream \& downstream flow for screen (case two).

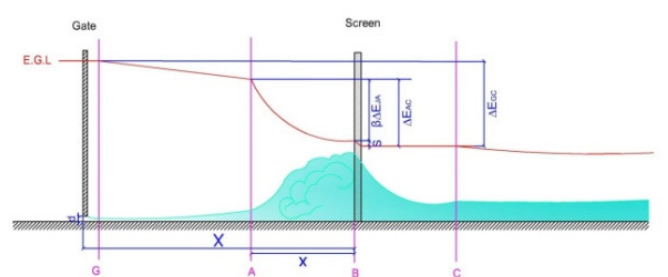

Figure (1). The general sketch for energy loss definition-Angle 90.

The definition of all the variables involved in the analysis presented below is depicted in Figure (1).

The energy loss between section (A) and the screen, $\left(\boldsymbol{\Delta} \mathbf{E}_{\mathbf{A B}}\right)$, is computed by using the below expressions (Çakır, P. 2003).

$$
\Delta E_{A B}=\beta \Delta E_{j A}
$$

Where $\left(\Delta \boldsymbol{E}_{j A}\right)$ is defined as energy loss due to a full jump that could be formed at section (A). The formula above is developed on the assumption that, the loss $\left(\Delta \boldsymbol{E}_{\boldsymbol{A} \boldsymbol{B}}\right)$ is some function of the distance from the upstream end

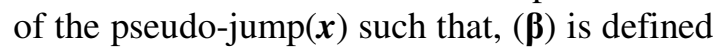
as (Çakır, P. 2003).

$\beta=q^{\left(1-\frac{1}{\alpha}\right)}$

\section{Where:}

$\alpha=\frac{x}{L}$

For $\mathrm{L}>\mathrm{x}, 0<\beta<1$

For $\mathrm{L} \leq \mathrm{x}, \beta=1$

With (L) being the length of a jump if there were a full jump at section (A). The reason an exponential form is adopted, is to take into account the extremities, full jump (Case One) and impinging jet, and pseudo-jump formation (Case Two).

In equation (3.3), (L) is related to the $\left(\mathbf{F r}_{\mathbf{A}}\right)$, after French (1986) (French, R.H. 1986). as

$L=9.75 y_{A}\left(F r_{A}-1\right)^{1.01}$ 
$F_{r_{A}}=\frac{V_{A}}{\sqrt{g y_{A}}}$

where $\left(\mathbf{y}_{\mathbf{A}}, \mathbf{F r}_{\mathbf{A}}, \mathbf{V}_{\mathbf{A}}\right)$ are the flow depth, Froude number and flow velocity respectively at section (A) and (g) is the gravitational acceleration.

The energy loss at the screen $(\mathbf{S})$, is calculated, as (Çakır, P. 2003).

$s=\Delta E_{A C}-\Delta E_{A B}$

$s-\left(y_{A}+\frac{v_{g}^{2}}{2 g}\right)-\left(y_{c}+\frac{v_{c}^{2}}{2_{g}}\right)-\rho \Delta \varepsilon_{j A} \quad \ldots \ldots(\gamma)$

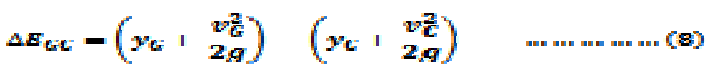

$y_{G}=c_{v} d$

And $\mathbf{C}_{\mathbf{V}}=\mathbf{0 . 6 2 5}$ after Simon (1981) (Simon, A.L. 1981).

Efficiency of the system is calculated as (Çakır, P. 2003).

$n_{s y s}=\frac{\left(\Delta E_{G C}-\Delta E_{j G}\right)}{\Delta E_{j E}}$

where $\left(\boldsymbol{\Delta E}_{\mathbf{j G}}\right)$ is defined as energy loss due to a hypothetical full jump that could have formed at section $(\mathbf{G})$.

Efficiency of the screen is calculated as (Çakır, P. 2003).

$\mathrm{I}_{s o r}=\frac{5}{\Delta E_{j G}}$

\section{Dimensional Analysis:}

The screen energy loss $(\mathbf{S})$, depends on the variables mentioned below, and can be expressed as the following relation:

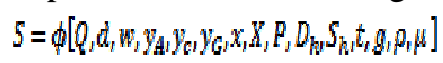

When.

S:energy head dissipated due to screen, [L],

Q: discharge, $\left[\mathrm{L}^{3} \mathrm{~T}^{-1}\right]$,

d: gate opening, [L],

w: width of the channel, [L],

$\mathbf{y}_{\mathbf{G}}$ : water depth at Section $\mathrm{G},[\mathrm{L}]$,

$\mathbf{y}_{\mathrm{A}}$ : water depth at Section A, [L],

$\mathbf{y}_{\mathbf{C}}$ : water depth at Section C, [L],

$\boldsymbol{x}$ : the distance from the upstream end of the pseudo-jump to the screen, [L],

$\mathbf{X}$ : distance between the screen and the gate, [L],

p: porosity of the screen,

$\mathbf{D}_{\mathbf{h}}$ : Inside diameter of circular holes in the screen, [L],

$\mathbf{S}_{\mathbf{h}}$ : Inside length of square holes in the screen, [L], $\mathbf{t}$ : thickness of the screen, [L],

g: gravitational acceleration, $\left[\mathrm{LT}^{-2}\right]$,

$\boldsymbol{\rho}$ : density of water, $\left[\mathrm{ML}^{-3}\right]$,

$\boldsymbol{\mu}$ : dynamic viscosity of water, $\left.\left[\mathrm{ML}^{-1} \mathrm{~T}^{-1}\right)\right]$

Recalling the fact that the slug length $(\mathbf{L})$ and

$\left(\mathbf{F r}_{\mathbf{C}}\right)$, Froude number at section $(\mathbf{C})$, are functions of:

$L=\phi\left[Q, d, w, y_{A}\right]$

$F r_{C}=\phi\left[Q, d, w, y_{c}\right]$

By replacing $\left(\mathbf{y}_{\mathbf{A}}\right)$ and $\left(\mathbf{y}_{\mathbf{C}}\right)$ in Equation (12) by $(\mathbf{L})$ and $\left(\mathbf{F r}_{\mathbf{C}}\right)$ in Equations (13)\& (14) respectively.

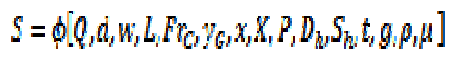

By dimension analysis:

$\frac{s}{y_{G}}=\phi\left[\frac{w}{y_{G}}, F r_{G} \frac{L}{y_{G}}, F r_{G}, \frac{x}{y_{G}}, \frac{X}{y_{G}}, p_{2} \frac{D_{h}}{y_{G}}, \frac{s_{h}}{y_{G}}, \frac{t}{y_{G}}, R e\right]$

where (Re) is the Reynolds number.

In addition, recalling the fact that $\left(\mathbf{E}_{\mathbf{G}}\right)$, energy at $\operatorname{section}(\mathbf{G})$, having the length dimension is a function of:

$E_{G}=\phi\left[0, d, w, g, y_{G}\right]$

By dimension analysis:

$\frac{E_{G}}{y_{G}}=\phi\left[\frac{d}{y_{G}}, \frac{w}{y_{G}}, F \psi_{G}\right]$

As seen from Equation (18) $\left(\frac{E_{G}}{y_{G}}\right)$ is function of $\left(\frac{w}{y_{G}}\right)$ therefore Equation (18) Can be rewritten by replacing $\left(\frac{w}{y_{G}}\right)$ with $\left(\frac{E_{G}}{y_{G}}\right)$.

$\frac{S}{y_{e}}=\phi\left[\frac{E_{G}}{y_{e}}, F r_{G} \frac{L}{y_{e}}, F r_{C} \frac{x}{y_{e}}, \frac{X}{y_{e}}, P, \frac{D_{k}}{y_{e}}, \frac{S_{k}}{y_{e}}, \frac{t}{y_{e}}, R e\right] \ldots$

The above equation can be put in a more convenient form such that

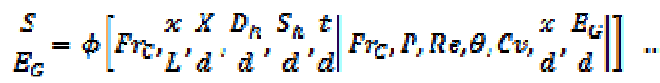

$\frac{\boldsymbol{x}}{\boldsymbol{L}}$ was defined as $\alpha$ in Equation (3)

Can be dropped out of those parameters from the equation (20) as variables:

- The parameters $\left(\boldsymbol{F r}_{\mathbf{C}}\right),\left(\frac{\boldsymbol{E}_{\mathrm{G}}}{\boldsymbol{d}}\right)$ and $\left(\frac{\boldsymbol{x}}{d}\right)$ are beyond the scope of the search.

- $\left(\mathbf{C}_{\mathbf{v}}\right)$, which defined as $\left(\frac{y_{G}}{d}\right)$ is a constant. 
- The Reynolds number $(R e)$ is assumed to be negligible, since the magnitude of $\left(\mathrm{Fr}_{\mathrm{G}}\right)$ is relatively high in the range covered during the experiments of this free surface flow study in which gravitational effects are more dominant,

- The porosity $(\mathrm{P})$, showed that porosity of $40 \%$ (optimum porosity)

Then, Equation (20) can further be reduced into the following form

$\frac{S}{E_{C}}=\phi\left[F T_{G}, \alpha, \frac{X}{d}, \frac{D_{h}}{d t}, \frac{S_{k}}{d^{\prime}}, \frac{t}{d}\right]$

That is, the present experimental study is carried out by taking into account the following dimensionless parameters:

$$
F r_{G}, \alpha, \frac{X}{d}, \frac{D_{k}}{d}, \frac{S_{h}}{d}, \frac{z}{d}
$$

\section{Experimental work:}

The apparatus and instruments used in this study are mentioned in this chapter as described below each in detail.

\section{The Flume:}

The experiments were conducted on a smooth toughened glass sided and smooth painted bed steel plate flume of $12 \mathrm{~m}$ working length. The flume cross sectional area is $50 \mathrm{~cm}$ wide and $50 \mathrm{~cm}$ deep. The longitudinal slope of the Flume can be adjusted mechanically by two hydraulic jacks raised and lowered manually to establish the required slope. At the downstream end, the flume was equipped with a vertically moving tail gate to control the tail water depth. A pair of steel pipe rails was fixed on the top of the side walls throughout the working length to support the point gages. The upstream end of the flume was connected to the stilling basin of internal dimensions $(2.5 \mathrm{~m}$ length, $0.70 \mathrm{~m}$ width and $0.87 \mathrm{~m}$ depth) by a smooth thin steel plate, provided at its end with a serious of alternate mesh screens to dissipate the energy of the incoming flow from the overhead tank. Water supplied to the flume from an underground concrete storage tank of internal dimensions (7.5 m length, $2.5 \mathrm{~m}$ width and $1.0 \mathrm{~m}$ depth). Water drawn from the underground storage tank by an electrically driven centrifugal pump through a 6 inch diameter Steel pipe to the overhead tank providing a total discharge of
(50 lit/sec). Photo (2) and Fig (3) shows the Flume Khurshed, O.M. (2010).

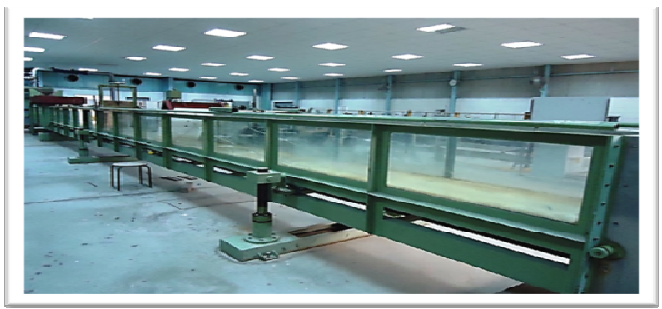

Photo (2). The Flume.

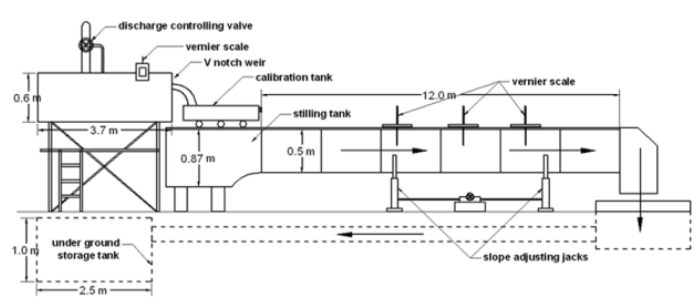

Figure (3): The Flume.

\section{The Overhead Tank:}

A box shape tank of internal dimensions 3.7 $\mathrm{m}$ length, $0.8 \mathrm{~m}$ width and $0.6 \mathrm{~m}$ depth, made from thick steel plate fixed on a steel frame elevated to the required height. Water that pumped into the overhead tank passes through a serious of alternate mesh screens to dissipate its turbulence and energy before reaching the upstream of the V-notch weir and overflowing to the flume, discharge controlled by two control valves one of $6 "$ dia. and the other of 1.5" dia (Khurshed, O.M. 2010).

\section{The V-notch weir:}

The discharge in the Flume was measured by means of a V-notch weir located at the end of the overhead tank. The head of water above the V-notch was measured by a point gage with a vernier scale of $0.05 \mathrm{~mm}$ accuracy located $80 \mathrm{~cm}$ upstream of the $\mathrm{V}$-notch weir placed in a small box tank fixed to the right side of the overhead tank and connected from bottom to the overhead tank so that the depth of water in the side tank is the same in the overhead tank and the water surface is in static condition (Khurshed, O.M. 2010).

\section{The measuring tank:}

A box shape tank manufactured for calibrating the head-discharge relation of the V-notch weir, the calibration tank manufactured with internal dimensions $(1.5 \mathrm{~m}$ 
length, $1 \mathrm{~m}$ width and $0.3 \mathrm{~m}$ height) to store about 300 liters, the tank provided with six rollers (three in each side) to facilitate its movement. The tank placed downstream of the V-notch weir and fast pulled when filled by water, the time was recorded by a stop watch of $0.01 \mathrm{sec}$ accuracy. In each run the volume of water, time and the head above the V-notch was recorded (Khurshed, O.M. 2010). For several water depths above the V-notch weir between (5 to about $28 \mathrm{~cm}$ ), the measuring tank placed under the weir and for a reasonable volume of water the time was recorded.

$$
Q=0.0195 h_{v}{ }^{279 R}
$$

\section{Point gages for depth measurement:}

The water depth in the test flume was measured by means of three precision point gauges .The vernier scale of the point gages permitted depth readings with an accuracy of $0.05 \mathrm{~mm}$. The point gages were mounted on a carriage which moved on a pair of rails fixed on the top of the side walls of the test flume. This traversing arrangement enable three degree freedom of movement and enabled the gage reading at any arbitrary point in the area of interest to be taken by moving the carriage and the point gage.

\section{The sluice gate:}

The sliding gate located at the bottom of the pressurized tank acts like a sluice gate and ensures the upstream supercritical flow conditions necessitated for the study. Froude number range covered during the study is from 5.0 to 25 . The gate opening is adjusted at heights of $1.0 \mathrm{~cm}, 2.0 \mathrm{~cm}$ and $3.0 \mathrm{~cm}$ during the study. All the initial energy calculations are done with respect to the depth at vena contracta.

\section{The screens:}

The material used for screens is Plexiglas, which is chosen for its easy handling property. The thickness of the screens is $1 \mathrm{~cm}$ and they have a porosity of $40 \%$, which is achieved by two types of holes, circular $1 \mathrm{~cm}$ diameter holes and square $1 \mathrm{~cm}$ length of side arranged with a uniform mesh. During the study experiments with only single and double screen arrangement. In the present work, one screen arrangements is used, which is one screen and one double screen arrangements. In single screen and double screen arrangement by perpendicular, the effects of the relative screen position, $\mathrm{X} / \mathrm{d}$, and the relative screen thickness, $t / d$ are examined by changing the height of the sliding gate opening, and the locations of the screens.

\section{Experimental procedure:}

The experimental runs performed for single screen and one double screen arrangement. The $\mathrm{X}$ values and gate openings are determined as given in Table (1) for single and one double screen arrangement.

\begin{tabular}{|c|c|c|c|}
\hline$\frac{\mathbf{x}}{\boldsymbol{d}}$ & $\mathbf{d = \mathbf { 1 }}$ & $\mathbf{d = 2} \mathbf{~ c m}$ & $\mathbf{d = 3} \mathbf{~ c m}$ \\
\hline 50 & $50^{*}$ & 100 & 150 \\
\hline 100 & 100 & 200 & 300 \\
\hline
\end{tabular}

Table (1): Nominal X value.

*Ignoring this value

For each specified set of experiments, the location of the screen is arranged sothat desirable $\mathrm{X} / \mathrm{d}$ values are obtained. For a given location of the screen, the height of the sliding gate opening is changed providing proper experiment set and consistent $\mathrm{t} / \mathrm{d}$ values. After the location of the screen and gate opening are fixed, discharge is regulated by means of the valve situated on the supply pipe between the pressure tank and the V-notch weir. For each set of experiment, several Froude number values are adjusted between predetermined maximum and minimum Froude number values. The Range of Froude number between ( 5-25) but in some set of experiments this value is exceeded because the minimum Froude number value is high, and enough number of experiments for reasonable results cannot be achieved in this range. The minimum Froude number value is determined as the water start to choke the gate for the specified discharge for one double screen arrangement. The choking of the gate may start either by lowering the discharge too much and hence the upstream flow Froude number. In case of one double screen arrangement, the experiments are performed 
with the upstream sliding gate being submerged for a wide range of Froude numbers.

In addition, for each discharge value, depth measurements are taken on predetermined sections, namely at points $\mathrm{G}, \mathrm{A}, \mathrm{B}$ and $\mathrm{C}$ for single and one double screen, by means of a mobile point gage at three points along the width of the channel.

All depth measurements and all calculations are repeated and the control gate opening is adjusted for the new series of experiments. Finally, the screen is moved to the next scheduled location and the same procedure is performed at the new location.

\section{Results and Discussion:}

Comparison between circular holes and square holes:

\section{Performace of the system:}

As indicated before the total energy loss between the exit of the gate and the downstream of the screen is denoted as $\left(\Delta \mathbf{E}_{\mathbf{G C}}\right)$ This energy loss includes the friction losses, losses due to the pseudo-jump and the screen loss. The relative energy loss $\left(\Delta \mathbf{E}_{\mathbf{G C}} / \mathbf{E}_{\mathbf{G}}\right)$ is used to analyze the system performance.

From the graphics, one may discern that:

- The performance of system $\left(\Delta \mathbf{E}_{\mathbf{G C}} / \mathbf{E}_{\mathbf{G}}\right)$ increases with increasing of Froude number (FrG) for both types of holes.

- There are no apparent differences observed in the system performance in both types of holes.

- There are no siginificant of perfomance of system on relative screen postion $(\mathrm{X} / \mathrm{d})$.

- There are no siginificant of perfomance of system on screen thickness (t).

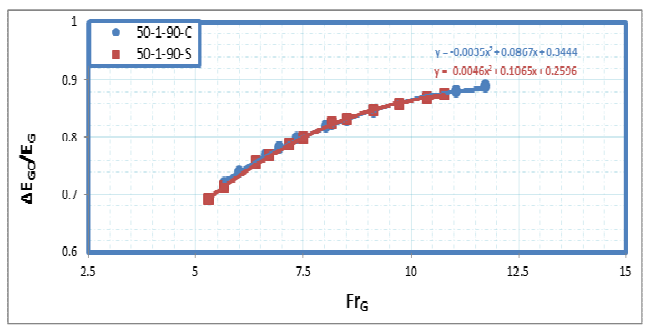

Figure (4): for $\Delta \mathrm{E}_{\mathrm{GC}} / \mathrm{E}_{\mathrm{G}} \mathrm{Vs} \mathrm{Fr}_{\mathrm{G}}$ For $\mathrm{X} / \mathrm{d}=50$, single screen.

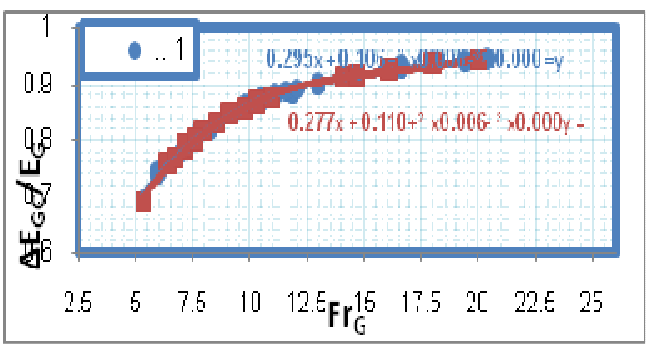

Figure (5): for $\Delta \mathrm{E}_{\mathrm{GC}} / \mathrm{E}_{\mathrm{G}} \mathrm{Vs}_{\mathrm{S}} \mathrm{Fr}_{\mathrm{G}}$ For $\mathrm{X} / \mathrm{d}=100$, single screen.

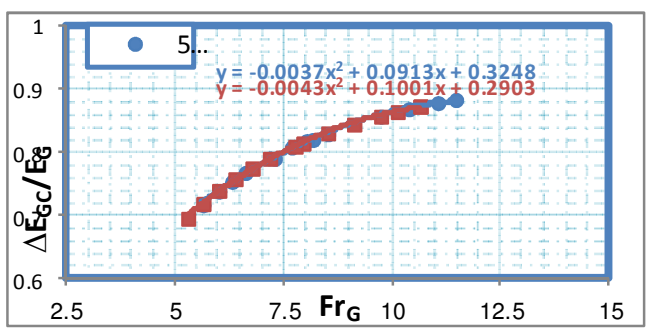

Figure (6): for $\Delta \mathrm{E}_{\mathrm{GC}} / \mathrm{E}_{\mathrm{G}}$ Vs $\mathrm{Fr}_{\mathrm{G}}$ For $\mathrm{X} / \mathrm{d}=50$, double screen.

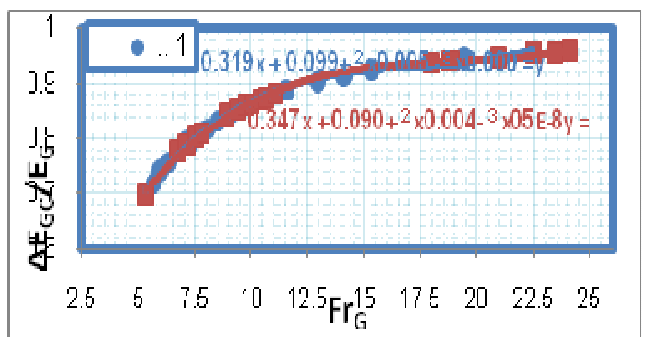

Figure (7): for $\Delta \mathrm{E}_{\mathrm{GC}} / \mathrm{E}_{\mathrm{G}} \mathrm{Vs} \mathrm{Fr}_{\mathrm{G}}$ For $\mathrm{X} / \mathrm{d}=100$, double screen.

\section{Performace of the screen:}

As indicated before the energy loss at the screen is denoted as $(\mathbf{S})$. The relative energy loss $\left(\mathbf{S} / \mathbf{E}_{\mathbf{G}}\right)$ is formulated to represent the screen performance.

\section{From the graphics, one may discern that:}

- The performance of screen $\left(\mathbf{S} / \mathbf{E}_{\mathbf{G}}\right)$ decreases with increasing of Froude number $\left(\mathbf{F r}_{\mathbf{G}}\right)$ for both types of holes

- Performance of screen with square holes in dissipate the energy is more than as compared to performance of screen with circular holes under different conditions of $(\mathbf{t}, \mathbf{X} / \mathbf{d})$.

- As $(\mathbf{X} / \mathbf{d})$ increases the different in $\left(\mathbf{S} / \mathbf{E}_{\mathbf{G}}\right)$ between tow types of holes decrease as show in figures, under condition of $(\mathbf{t})$. 
- There are no significant effects of screen thickness (t) on the screen under condition of ( $\mathbf{X} / \mathbf{d})$.

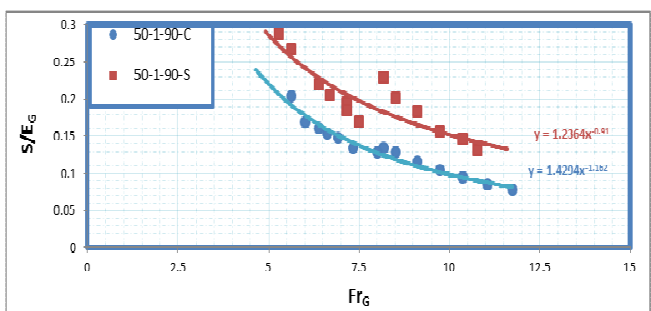

Figure (8): for $S / E_{G} V_{s} F_{G}$ For $X / d=50$, single screen.

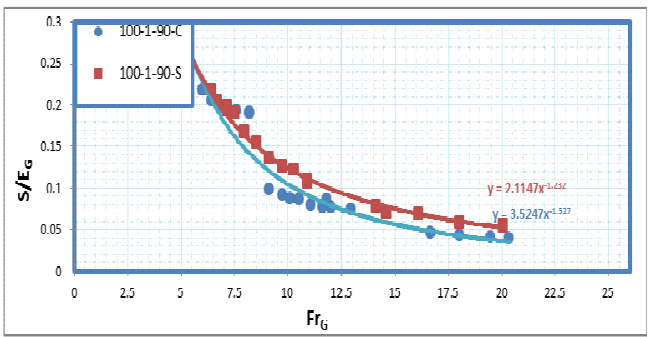

Figure (9): for $\mathrm{S} / \mathrm{E}_{\mathrm{G}} \mathrm{Vs}_{\mathrm{Fr}}$ For $\mathrm{X} / \mathrm{d}=100$, single screen.

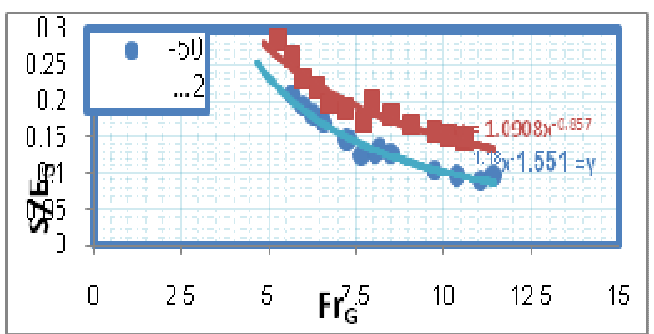

Figure (10): for $S / E_{G} V_{s} F_{G}$ For $X / d=50$, double screen.

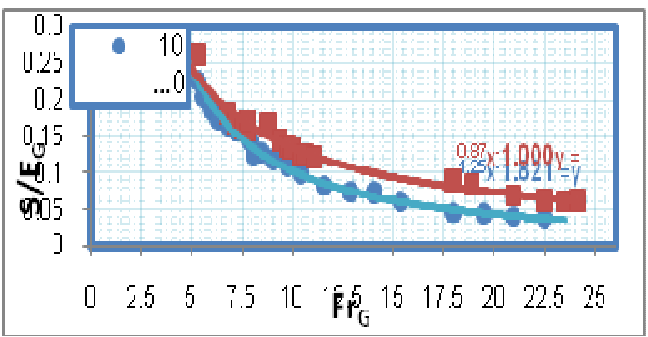

Figure (11): for $S / E_{G} V_{s} F_{G}$ For $X / d=100$, duoble screen.

\section{System efficiencies:}

In other words system efficiency is the ratio of the difference between the system loss and the loss through a hypothetical jump at section (G) to the loss through the

hypothetical jump. Therefore, this alternative interpretation of the data in terms of system loss does not posses any new information.

From the graphics, one may discern that:

- The efficiency of system $\left(\square_{\text {sys }}\right)$ decreases with increasing of Froude number $\left(\mathbf{F r}_{\mathbf{G}}\right)$ for both types of holes.

- The efficiency of system ( $\square$ sys $)$ for screen with square holes in dissipate the energy is more than as compared to The efficiency of system $\left(\square_{\text {sys }}\right)$ for screen with circular holes.

- As the relative screen position (X/d) increases the different in efficiency of system $(\square$ sys $)$ between tow type of hole decrease as show in figures, under condition of (t).

- There are no significant effects of efficiency of system ( $\square$ sys $)$ on screen thickness ( $(\mathbf{t})$ under condition of ( $\mathbf{X} / \mathbf{d})$.

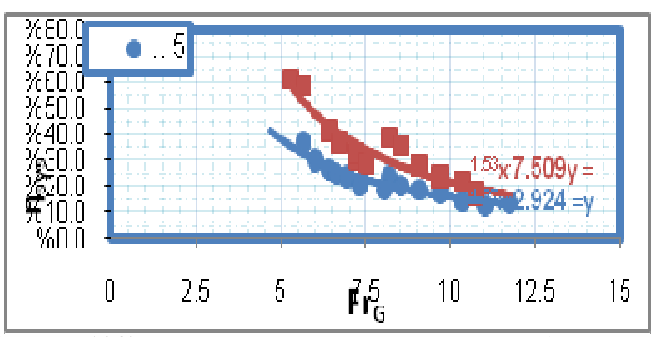

Figure (12): for $\square_{\text {sys }}$ Vs $\operatorname{Fr}_{\mathrm{G}}$ For $\mathrm{X} / \mathrm{d}=50$, single screen.

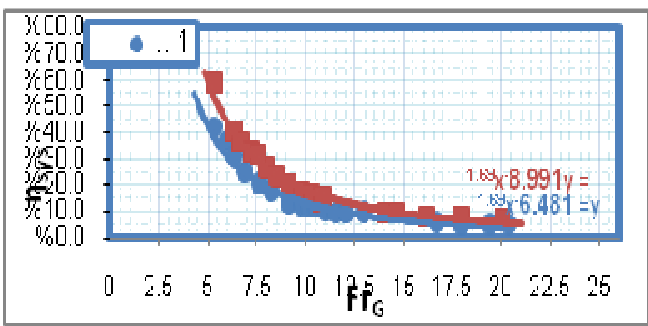

Figure (13): for $\square_{\text {sys }} \operatorname{Vs~Fr}_{\mathrm{G}}$ For $\mathrm{X} / \mathrm{d}=100$, single screen.

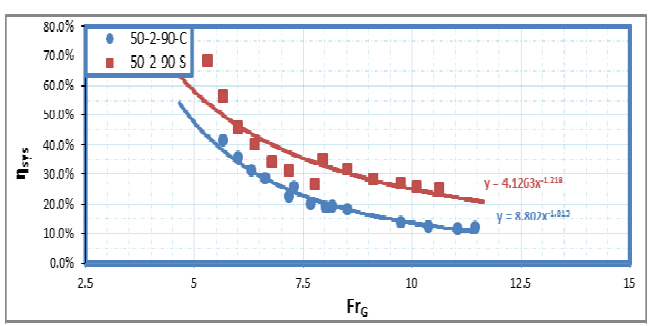

Figure (14): for $\square_{\text {sys }} \mathrm{Vs} \mathrm{Fr}_{\mathrm{G}}$ For $\mathrm{X} / \mathrm{d}=50$, double scree. 


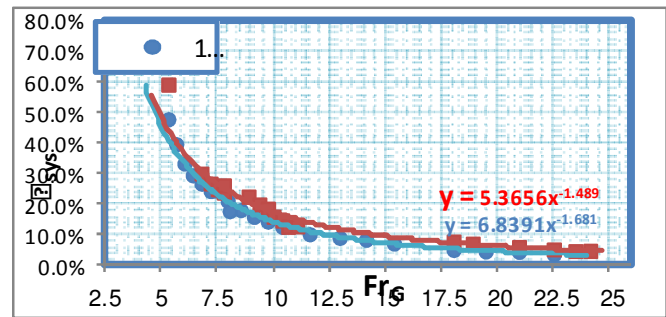

Figure (15): for $\square_{\text {sys }} \mathrm{Vs}_{\mathrm{s}} \mathrm{Fr}_{\mathrm{G}}$ For $\mathrm{X} / \mathrm{d}=100$, double screen.

\section{Screen efficiencies:}

In other words screen efficiency is the ratio of the loss through the screen to the loss through the hypothetical jump at section (G). Therefore, this alternative interpretation of the data in terms of screen loss does not posses any new information.

\section{From the graphics, one may discern that:}

- The efficiency of screen $\left(\square_{\text {scr }}\right)$ decreases with increasing of Froude number $\left(\mathbf{F r}_{\mathbf{G}}\right)$ for both types of holes.

- The efficiency of screen $\left(\square_{\text {scr }}\right)$ with square holes in dissipate the energy is more than as compared to The efficiency of screen $\left(\square_{\text {scr }}\right)$ with circular holes.

- As the relative screen position $(\mathbf{X} / \mathbf{d})$ increases the different in $\left(\square_{\text {scr }}\right)$ between tow types of holes decrease as show in figures, under condition of (t).

- There are no significant effects of efficiency of screen $\left(\square_{\text {scr }}\right)$ on screen thickness (t) under condition of $(\mathbf{X} / \mathbf{d})$.

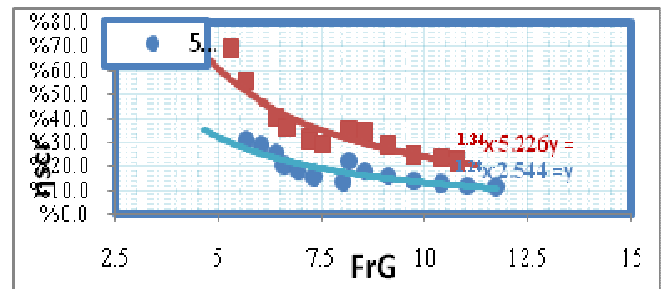

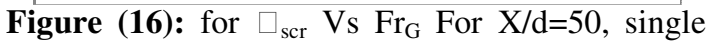
screen.

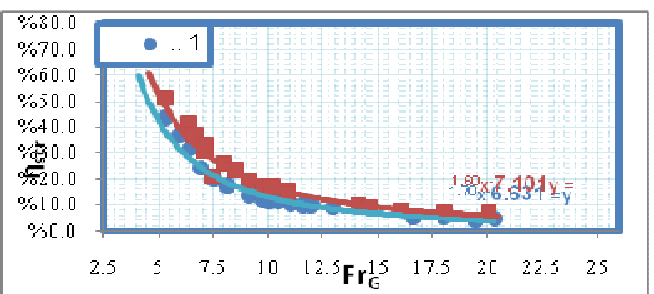

Figure (17): for $\square_{\text {scr }} \operatorname{Vs}_{F_{G}}$ For $X / d=100$, single screen.

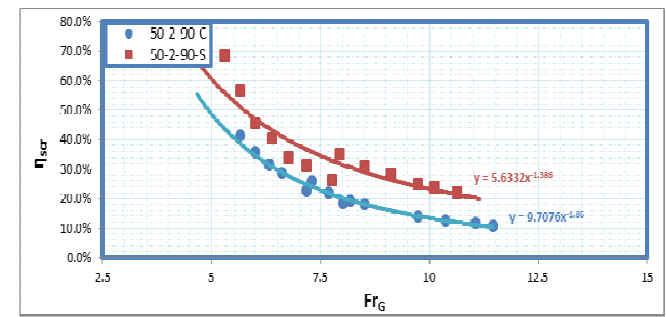

Figure (18): for $\square_{\text {scr }} \mathrm{Vs}_{\mathrm{S}} \mathrm{Fr}_{\mathrm{G}}$ For $\mathrm{X} / \mathrm{d}=50$, double screen.

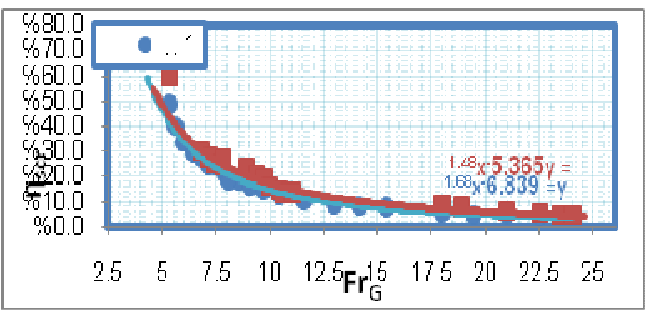

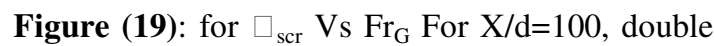
screen.

\section{Conclusions:}

The following conclusions can be drawn from the analysis of the experimental data of the study:

- The performance of system $\left(\Delta \mathbf{E}_{\mathbf{G} C} / \mathbf{E}_{\mathbf{G}}\right)$ increases with the increasing of Froude number $\left(\mathbf{F r}_{\mathbf{G}}\right)$ for both types of holes.

- The efficiency of system $\left(\square_{\text {sys }}\right)$ decreases with the increasing of Froude number $\left(\mathbf{F r}_{\mathrm{G}}\right)$ for both type of holes.

- The efficiency of system ( $\left.\square_{\text {sys }}\right)$ for screen with square holes is better than the efficiency of system $(\square$ sys $)$ for screen with circular holes in dissipate the energy under same conditions of ( $\mathbf{t}, \mathbf{X} / \mathbf{d})$.

- The performance of screen $\left(\mathbf{S} / \mathbf{E}_{\mathbf{G}}\right) \&$ The efficiency of screen $\left(\square_{\text {scr }}\right)$ decreases with increasing of Froude number $\left(\mathbf{F r}_{\mathbf{G}}\right)$ for both type of holes.

- The performance of the screen $\left(\mathbf{S} / \mathbf{E}_{\mathbf{G}}\right) \&$ The efficiency of screen $\left(\square_{\text {scr }}\right)$ with square holes is better than performance of the screen with circular holes in dissipate the energy under same conditions of $(\mathbf{t}$, $\mathrm{X} / \mathrm{d}$ ).

\section{References:}

Balkış, G. (2004). "Experimental Investigation of Energy Dissipation Through Inclined Screens". MSc Thesis, Department of Civil Engineering, 
Middle East Technical University, Ankara, Turkey.

Bozkuş, Z., Çakır, P., Ger, M. and Özeren, Y. (2004). "Energy Dissipation Through Screens "Proceedings of ASCE World Water \& Environmental Resources Conference 2004, Salt Lake City, Utah, U.S.A.

Ted Chu, Graduate Mentor and K.H., Wang, Faculty Mentor (2007). " Study of the Head Loss Associated with a Fluid Flowing through a Porous Screen", final report, Department of Civil and Environmental Engineering, University of Houston Houston, Texas, Sponsored by the National Science Foundation REU Program.
Çakır, P. (2003). "Experimental Investigation of Energy Dissipation Through Screens". MSc Thesis, Department of Civil Engineering, Middle East Technical University, Ankara, Turkey.

French, R.H. (1986). "Open Channel Hydraulics." McGraw-Hill Book Company, Singapore.

Simon, A.L. (1981). "Practical Hydraulics." John Wiley and Sons, Inc.,Toronto, Canada.

Khurshed, O.M. (2010). "Flow Characteristics Through Pipe Culvert Combined With Broad Crested Weir "MSc Thesis, Department of Civil Engineering, Collage of Engineering, University of Salahaddin.

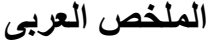

\section{تأثير اختلاف أشكال التثقيب المنظلي على تبديد الطاقة من خلال الخلايا المنخلية العمودية}

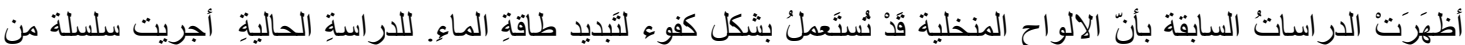

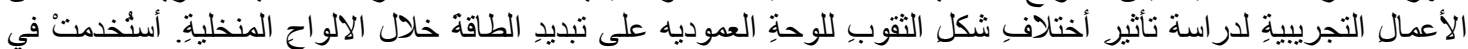

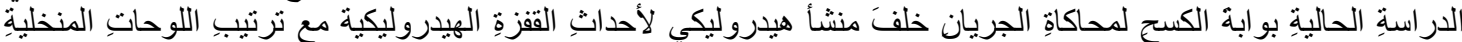

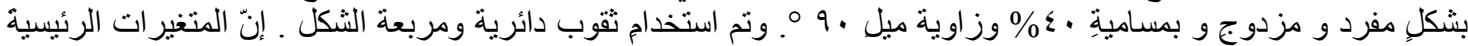

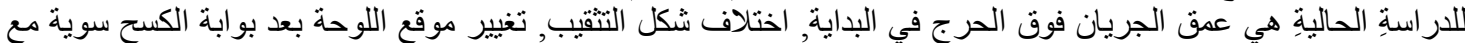

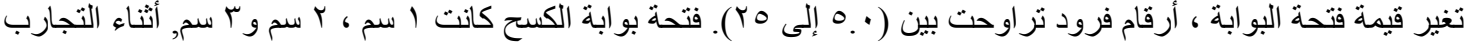

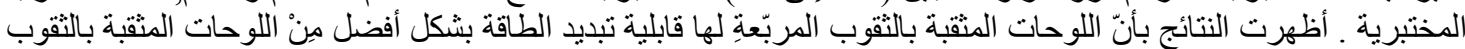

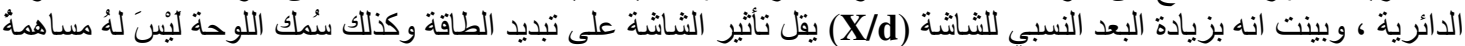

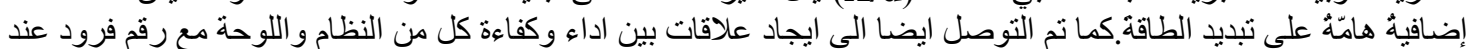

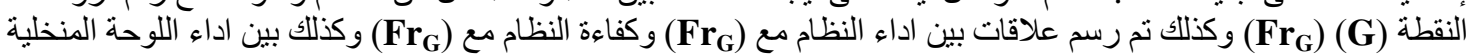

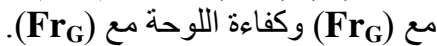

الكلمات الدالة: اللوحة المنخلية، تبديد الطاقِة، ثقوب دائرية، ثقوب مربّعة، القفزة الهيدروليكية, جريان فوق الحرج. 